\title{
A test of the competing response-interference hypothesis of extinction'
}

John Theios, UNIVERSITY OF TEXAS

Gordon H. Bower, STANFORD UNIVERSITY

\begin{abstract}
Abstraet
Following training in a runway, two groups of rats were either confined in the goal box for 20 sec. during extinction trials or permitted to immediately jump out of the goal box. Contrary to the predictions of the interference theory, there were no differences between the groups in resistance to extinction. Within the jump group there was a moderate degree of covariation between jump frequency and resistance to extinction. However, this relationship can be explained by differences in general activity level rather than response interference.
\end{abstract}

\section{Problem}

Adelman \& Maatsch (1955) reported that a goalapproach response does not extinguish when rats are permitted to escape (jump out) from a previously rewarded (but now empty) goal box. This result has been cited in several sources as favoring an interference theory of extinction (e. g., Kimble, 1961; Lawson, 1960). According to the interference theory, if the response elicited by frustrative nonreward is compatible with the previously rewarded response, then that response should not extinguish when reward is omitted. Likewise, the more incompatible responses elicited by nonreward, the faster should the instrumental response extinguish.

There are several findings in the literature which are at variance with the Adelman \& Maatsch results and the interference theory of extinction. Klugh (1961) found that rats removed from the goal area immediately during extinction were 1 ess resistant to extinction than groups detained in the goal box. Hulse (1958) found no difference in resistance to extinction between groups detained in the goal box $10 \mathrm{sec}$. and groups detained $30 \mathrm{sec}$. Stanley \& Rowe (1954) found that goal box confinements of 10,30 , and $60 \mathrm{sec}$. did not result in different rates of extinction, but only in different asympotic extinction response times. On the basis of the Adelman \& Maatsch results and the interference theory, it would be expected that the longer the goal box confinement time the faster would be the rate of extinction. The present experiment attempts to confirm the Adelman \& Maatsch finding by comparing runway extinction of rats locked in the non-rewarded goal box with that of rats permitted to escape from the goal box.

\section{Method}

Twenty-one 180 day old male albino rats, maintained on a $22 \mathrm{hr}$. food deprivation schedule, were trained to run down a straight runway for a $.10 \mathrm{gm}$ food reward. The runway was 5 in wide by 5 in high by 96 in long.
The first and last 12 in comprised the start and goal boxes, respectively. Running time was measured to $.10 \mathrm{sec}$. from the opening of the start door until S interrupted a photobeam 3 in inside the goal box. After 30 rewarded trials, at five per day, response speeds were asymptotic. Ss were then assigned to two groups equated on performance over Trials 21-30. Ten Ss were assigned to the "Lock-in" extinction condition. On nonrewarded trials, these Ss were detained $20 \mathrm{sec}$. in the nonrewarded goal box. Eleven Ss were assigned to the "Jump-out" extinction condition. These Ss were given $2 \mathrm{~min}$. in which to jump-out of the empty goal box onto a 3 in ledge. The $\mathrm{S}$ was removed 20 sec. after reaching the ledge. Each $\mathrm{S}$ was run five extinction trials per day with a 20 min. intertrial interval until he had had at least 30 extinction trials and had accumulated five trials of not entering the goal box within $60 \mathrm{sec}$. On these latter trials, $\mathrm{S}$ was placed in the goal box after 60 sec.

\section{Results and Diseussion}

Comparing the average running times over the 30 extinction trials, there were no group differences in extinction rates, Mean trials to the fifth $60 \mathrm{sec}$. trial did not differ (30.5 for the Jump-out Ss and 31.0 for the Lock-in $\mathrm{Ss})$. By a post $\mathrm{f}$ a c to analysis, the Jump-out Ss may be divided into six good jumpers and five poor jumpers. The average percentages of jumps were 99 and 38, respectively, for the two sub-groups. An S's jump-probability was a fair predictor of his extinction rate, as may be seen in Fig. 1 which gives mean response times during extinction for the good and poor jumpers and the Lock-in Ss. The Pearson correlation between percentage of jumps and trials to extinction criterion was .72. The mean trials to criterion was 37.0 and 22.6, respectively, for the good and poor jumpers. The mean of the poor jumpers is significantly low e r than that of the Lock-in Ss $(t, 2.85 ;$ df, $13 ; p<.02)$, whereas the good jumpers and Lock-in Ss do not differ significantly in trials to criterion ( $t, 1.71 ; \mathrm{df}, 14 ; \mathrm{p}>.10)$.

These results do not provide very convincing support for the conclusions of the Adelman \& Maatsch (1955) experiment. Their Jump-out Ss showed no signs of extinction over 30 nonrewarded trials. By contrast, our Jump-out Ss as a group extinguished at the same rate as our Lock-in Ss. The six good jumpers in our experiment jumped from the goal box on practically every trial; nevertheless, their running behavior extinguished at the same rate as the best five Ss (selected post facto) from the Lock-in group (mean trials to criterion were 37.0 and 36.6 , respectively). 


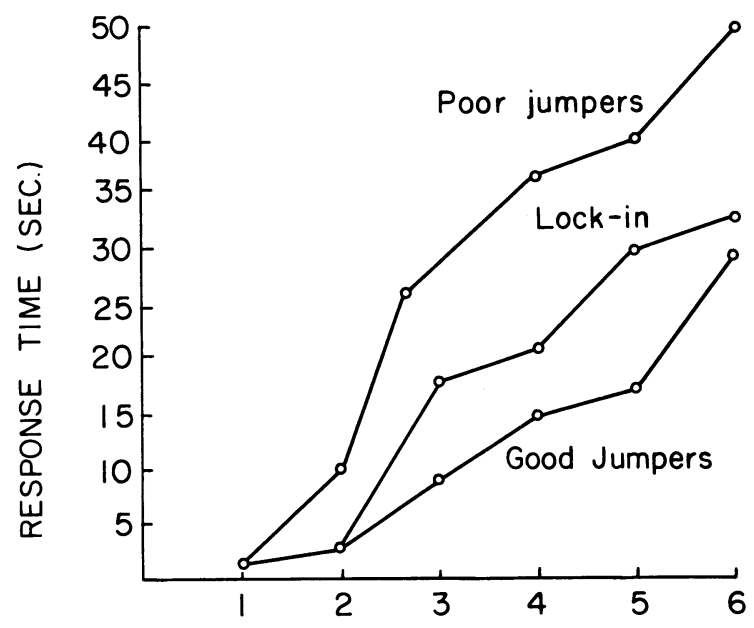

\section{DAILY BLOCKS OF 5 EXTINCTION TRIALS}

Fig. 1. Average running times during extinction plotted in daily blocks of five trial. The Jump-out group was divided into six good jumpers (bottom curve) and five poor jumpers (top curve).

What has been demonstrated is a moderate degree of covariation between runway performance and jumping out of the nonrewarded goal box. Such covariation admits of several interpretations alternative to the elicitationreinforcement interpretation of Adelman \& Maatsch. The covariation could be due to differences in general activity level. Active rats are probably more likely to both run fast and jump than lethargic rats.

Alternatively, it could be maintained that good Jumpout Ss remove themselves quickly from the cues evoking approach responses to the food cup, and thereby experience fewer nonrewarded goal responses $\left(r_{g}\right)$ each trial (cf. Logan et al, 1956). In order to hold this goal response hypothesis, however, it must be assumed that the Lock-in Ss were more successful than the poor jumpers in removing themselves from the cues evoking goal approach and $r_{g}$ since the poor jumpers (those Jump-out Ss less likely to leave the goal box) were significantly les s resistant to extinction than the Lockin group (those Ss who could not leave the goal box). This assumption seems tenuous since the poor jumpers physically removed themselves from the goal box on an average of $38 \%$ of the extinction trials, whereas the Lock-in Ss never left the box before the 20 sec. confinement time was up.

This experiment was the third unsuccessful attempt in our laboratories to obtain the "no extinction" result of the Adelman \& Maatsch jump-out procedure. If the failure to obtain the result is charged to differences in what are believed to be unimportant procedural detail (size of runway, trials per day), then the generality of the original finding is seriously questioned.

The present results suggest that during extinction, the event determining the decrement in the goal-approach response is the initial contact with the nonrewarded goal on each trial. Events and responses which occur subsequent to the initial nonreward appear to have little effect on rate of extinction. In the context of an $\mathbf{r}_{\mathrm{g}}$ hypothesis, the results suggest that the number $r_{g}$ 's evoked in the goal box on extinction trials is not an increasing function of confinement time.

\section{References}

ADELMAN, H. M., \& MAATSCH, J. L. Resistance to extinction as a function of the type of response elicited by frustration. J. exp. Psychol., 1955, 50, 61-65.

HULSE, S. H., JR. Amount and percentage of reinforcement and duration of goal confinement in conditioning and extinction. J. exp. Psychol., 1958, 56, 48-57.

KIMBLE, G. A. Hilgard and $\mathrm{Marqu}$ is' Conditioning and Learning. (2nd. ed.) New York: Appleton-Century-Crofts, 1961.

KLUGH, H. E. Speed of running in extinction as a function of differential goal box retention time. J. exp. Psychol., 1961, 61, 172-177.

LAWSON, R. Learning and Behavior. New York: Macmillian, 1960.

LOGAN, F. A., BEIER, E. M., \& KINCAID, W. D. Extinction following partial and varied reinforcement. J. exp. Psychol., 1956, 52, 65-70.

STANLEY, W. C., \& ROWE, M. I. Extinction by omission of food as a function of goal-box confinement. J.exp. Psychol., 1954, 48, 271-274.

\section{Note}

1. This research was supported by PHS Research Grants M-3849 and HD-00950 from the National Institute of Mental Health and the National Institute of Child Health and Human Development, Public Health Service. 